\title{
CORRECTION
}

\section{Correction: Sustained low efficiency dialysis using a single-pass batch system in acute kidney injury - a randomized interventional trial: the REnal Replacement Therapy Study in Intensive Care Unit PatiEnts}

\author{
Vedat Schwenger*1, Markus A Weigand², Oskar Hoffmann³, Ralf Dikow', Lars P Kihm', Jörg Seckinger', Nexhat Miftari', \\ Matthias Schaier', Stefan Hofer', Caroline Haar', Peter P Nawroth', Martin Zeier', Eike Martin and Christian Morath
}

See related research by Schwenger et al., http://ccforum.com/content/16/4/R140

\section{Correction}

The authors noticed after the publication of their article [1] an error in their methods. Under "Randomization and treatment assignments", the Asahi APS 650 membrane was used together with the Octo Nova device (Octo Nova, Diamed, Köln, Germany) and not the Prisma device as indicated in the manuscript. This section should therefore read as follows;

"Patients randomly assigned to the CVVH-group (Prisma, Gambro Hospal, Lyon, France and Octo Nova, Diamed, Köln, Germany) were treated with $35 \mathrm{ml} / \mathrm{kg}$ per hour replacement fluid in predilution. Treatment was scheduled for 24-h and blood flow was maintained between 100 and $120 \mathrm{ml} / \mathrm{min}$. For all CVVH treatments, high-flux filters (AN69-M100, Gambro Hospal, Lyon, France and Asahi Kasei APS-650, Asahi Kasei Medical Co, Ltd., Japan) were used."

In addition, the funding of this study was erroneously deleted in-house and should read as follows;

"Grant of the European Nephrology and Dialysis Institute, Bad Homburg, Germany".

\section{Competing interests}

VS, LPK, CM, MAW received lecture fees from Fresenius Medical Care, Germany. VS received scientific grants from Gambro Corporation Research, Germany.

The other authors have no conflict of interest with regards to the manufacture of the renal replacement therapy devices mentioned in the manuscript.

\begin{abstract}
Author details
'Department of Nephrology, University of Heidelberg, Im Neuenheimer Feld 672, Heidelberg 69120, Germany. ${ }^{2}$ Department of Anesthesiology, Justus-Liebig-University Giessen, Rudolf-Buchheim-Strasse 7, Giessen 35392, Germany. ${ }^{3}$ Section of Medical Statistics, University of Applied Science, Wiesenstrasse 14, Giessen-Friedberg 35390, Germany. ${ }^{4}$ Department of Anesthesiology, University of Heidelberg, Im Neuenheimer Feld 672, Heidelberg 69120, Germany. ${ }^{5}$ Department of Endocrinology, University of Heidelberg, Im Neuenheimer Feld 672, Heidelberg 69120, Germany.
\end{abstract}

\section{Published: 31 October 2012}

\section{Reference}

1. Schwenger V, Weigand MA, Hoffmann O, Dikow R, Kihm LP, Seckinger J, Miftari N, Schaier M, Hofer S, Haar C, Nawroth PP, Zeier M, Martin E, Morath C: Sustained low efficiency dialysis using a single-pass batch system in acute kidney injury - a randomized interventional trial: the REnal Replacement Therapy Study in Intensive Care Unit PatiEnts. Critical Care 2012, 16:R140.

doi:10.1186/cc11815

Cite this article as: Schwenger $V$, et al:: Correction: Sustained low efficiency dialysis using a single-pass batch system in acute kidney injury - a randomized interventional trial: the REnal Replacement Therapy Study in Intensive Care Unit PatiEnts. Critical Care 2012, 16:451.
*Correspondence: vedat.schwenger@med.uni-heidelberg.de

'Department of Nephrology, University of Heidelberg, Im Neuenheimer Feld 672, Heidelberg 69120, Germany

Full list of author information is available at the end of the article 